\title{
Crafting Personal Information - Resistance, Imperfection, and Self-Creation in Bullet Journaling
}

\author{
Jakob Tholander \\ Stockholm University \\ Stockholm, Sweden \\ jakobth@dsv.su.se
}

\author{
Maria Normark \\ Södertörn University \\ Stockholm, Sweden \\ maria.normark@sh.se
}

\begin{abstract}
Bullet journals are hand-written and self-created combinations of calendar, journal and planner. Central to this practice is how personal information is managed through a craft-based process. Based on a qualitative study, we discuss a set of themes that emerged in our analysis of this practice. We discuss how open-ended use of various materials for crafting of personal information engages in: 1) deliberate and strategic boundary work of what information to include and how combinations of data provide holistic and novel views of practitioner's life situations; 2) processes of self-creation and reflection on personal life trajectories; 3 ) appreciation of ourselves and the world around us as imperfect; and 4) ways of resisting the "business-like efficiency" that come with the large quantities of information that permeate contemporary life. We propose that this opens up new directions for thinking about how technologies of personal information may come into play in people's lives.
\end{abstract}

\section{Author Keywords}

Bullet journaling, crafts, personal informatics, imperfection, self-creation, analogue materials, making by hand.

\section{ACM Classification Keywords}

\section{CSS CONCEPTS}

- Human-centered computing Empirical studies in interaction design

\section{INTRODUCTION}

A bullet journal is a handwritten combination of calendar, todo list, habit tracker, and journal designed to organize personal information. It is created from a blank ordinary notebook, filled with self-made reoccurring information structures such as tables, lists, and logs, commonly combined with various personal decorations. Craft materials, such as pen, paper, tape, glue, stencils, and stickers are used to create

Permission to make digital or hard copies of all or part of this work for personal or classroom use is granted without fee provided that copies are not made or distributed for profit or commercial advantage and that copies bear this notice and the full citation on the first page. Copyrights for components of this work owned by others than ACM must be honored. Abstracting with credit is permitted. To copy otherwise, or republish, to post on servers or to redistribute to lists, requires prior specific permission and/or a fee. Request permissions from Permissions@acm.org.

CHI '20, April 25-30, 2020, Honolulu, HI, USA (C) 2020 Association for Computing Machinery. ACM ISBN 978-1-4503-6708-0/20/04 ...\$15.00 https://doi.org/10.1145/3313831.3376410 the journals, giving them a personal touch and creative aesthetics. It is described as a tool to manage and reflect on one's activities, tasks, goals and personal achievements, and in many ways resonates with contemporary demands on efficiency and productivity [28].

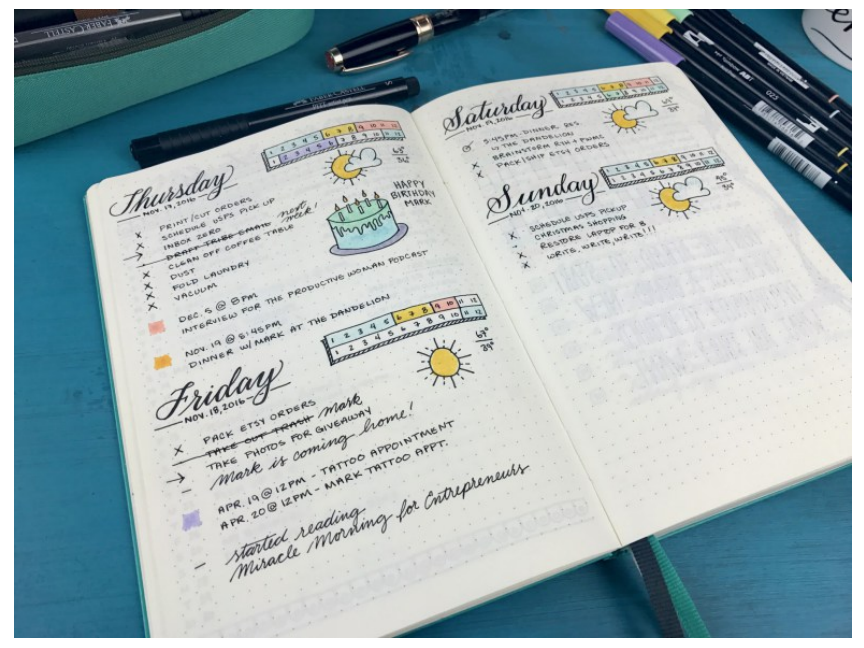

Figure 1: Spread from @bohoberry

Bullet journaling is a practice in which craft-based skills are mixed with the managing of personal information. By providing opportunities to engage with personal information in a fashion that revolves around personal crafting, continuously tweaked to individual needs and desires, bullet journaling represents a highly personal approach to managing personal information resembling the notion of lived informatics [58]. To understand the potentials of this practice for interaction design, we have investigated the lived experiences, strategies and practices that bullet journalists engage in when managing their everyday information, how information is made relevant, and the roles it plays in the practitioners' lives. These experiences turned out to be packed with the personally unique, manifested in a close relationship between the bullet journalists, their everyday information, and their social context. The analysis draws on the notion of experience and how it can be understood as the creation of coherent personal narratives for how people make sense of the world [48]. 
From our study of this practice a number of empirical themes emerged: 1) how crafting of personal information and design of information structures engages in deliberate and strategic boundary work of what kinds of information to include, and exclude, as well as how combinations of data provide novel and holistic views of their lives; 2) how crafting of personal information engages in deliberate self-creation and reflection on the personal trajectories they want to pursue; and 3) how open-ended use of various forms and materials for crafting of personal information allows for an appreciation of ourselves and the world around as imperfect and in the making; 4) how this practice engages in ways of resisting the "business-like efficiency" that come with the large quantities of information that permeate many aspects of contemporary life. Based on these findings, we discuss design opportunities around personal information that emerge.

\section{BACKGROUND}

Originally, bullet journaling was developed by a digital product designer, who wanted a quick paper-based system that would help improve productivity and personal efficiency $[14,15]$. It was spread through word of mouth and a Kickstarter campaign. At present, dedicated bullet journal supply departments are common both at stores online and art and craft stores. There are numerous Facebook groups and commercial events where people learn about bullet journaling and buy associated craft products.

Bullet journalists continuously tweak and reflect on the information they chose to include in their journals, depending on their personal needs, whims, influences and wishes in life. To do so, bullet journalists commonly share their designs with others and find new inspiration in Facebook groups, on Instagram and YouTube. Standing out in this practice is that despite being purely analogue in character, bullet journaling has become a popular way, especially amongst the generation of so-called digital natives [32] to manage their personal information. As a practice, bullet journaling can be situated in the context of research on every-day information management, hand-based crafting, and studies around discourses of productivity and selfimprovement. We frame bullet journaling in relation to these research contexts and tie into discourses on how boundaries of work life and leisure get increasingly blurred and how models of work efficiency leaks into other parts of life. Gregg has identified what she coins the "hegemony of productivity" and its relation to discourses around the self as an object for continuous reconsideration, improvement, and bootstrapping in order to maximize the potential of the individual [28]. In Giddens terms, contemporary society treats the self as a reflexive project that is constantly to be reinvented, adapted, and improved [27]. Relatedly, Lupton discusses how efforts of self-improvement and personal health creates ripples into the social and in everyday culture: "self-tracking may be viewed as one of many heterogeneous strategies and discourses that position the ideal individual as a responsible citizen, willing and able to take care of her or his self-interest and welfare."[46, p 79]
These trends on productivity and self-improvement has rendered critical work in $\mathrm{HCI}$, such as studies on productivity practices [43] and Purpura et al's [56] thought experiment on the design for the 'perfect individual'.

\section{Engaging with personal information}

The practice of bullet journal ties into research on technologies involving documentation, tracking, logging, and structuring of personal information. Previous work around bullet journaling in HCI have identified how this provides opportunities to address emotional and practical needs in a way that most mainstream personal informatics approaches do not [1]. The kinds of interaction that many such tools build upon does not align with the main driving forces behind bullet journaling. To unpack this, our study departs from research on personal informatics, an umbrella term that encompasses a variety of ways to document personal data, including calendars, sport tracking devices, personal photographs, stress management tools, health trackers and much more [17, 40, 58, 64]. Jones [36] defines personal informatics as the organization and maintenance of collections of personal information. Central to this research is so-called information curation, i.e., the strategies people use to store, manage and utilize their personal information [36]. To address the limitations of mainstream personal informatics research, proposed the notion of lived informatics with the aim to take a step away from the "technology centric" and often overly rational quest for the "objectively" true that much mainstream personal informatics rely on [58]. Instead, lived informatics draw on the subjective, lived and sometimes even irrational aspects common to people's use of personal information [58]. Williams' auto-ethnographic study of weight loss techniques make similar claims by revealing how our relationships to information and the world around us are largely irrational and contradictory, involving ongoing process of negotiation with ourselves as individuals [72]. More design-oriented studies have explored how people relate to self-chosen and self-designed data and how they account for it in everyday life [20, 21, 22]. This has involved explorations of how data in various forms can be used as a material and a resource for crafting novel forms of interaction $[19,54]$, which has also been explored in artistic settings such as the Dear data project [45]. Further studies of documentary information practices have identified how people develop aesthetic and sometimes even "poetic" relationships to their data [24]. Relatedly, [53] have shown how direct involvement with data through fabrication and manipulation influences the personal meaning people ascribe to it.

Studies of life logging and the quantified-self have contributed to understanding practices around personal data and the drivers that underlie people's engagement in meticulously collecting and keeping track of personal data and statistics [11, 20, 30, 47, 45]. Nafus \& Sherman discuss the highly personal ways of engaging with personal data [51]. One assumption shared among these practices is that engaging with personal data is a useful resource for self- 
reflection and has the power to influence users' broader life choices and contribute to making changes in life, $[30,72$, 51]. Relatedly, Lupton's work on data practices such as life logging proposes that in these settings of use, data becomes meaningful in individually unique ways simply for the reasons that the data is about and for users themselves [46]. The practices as such provide users with a sense that data is uniquely theirs. However, what one individual might find important and valuable is necessarily not so to someone else. By articulating and making sense of data in their own personal ways they come to understand things about themselves that they otherwise would not, bringing to the fore alternative values and usages of data that traditional information practices do not [51]. All in all, these perspectives suggest how the idiosyncrasies of the individual contribute to a way of looking at personal data that fundamentally differs from what is assumed by the predefined information structures provided by many common tools and technologies.

\section{Crafting and making by hand}

In the past decade, HCI and interaction design researchers have turned the attention to various aspects of crafting as a way of approaching interaction with novel materials. Commonly, we associate crafted objects as artefacts made with traditional methods and materials, often handmade through purposeful methods involving skills developed over time as well as a familiarity with the material properties [4]. A few examples among the large number of technologies and studies of crafting in HCI include Dew and Rosner's study of woodwork [18], Meissner and Fitzpatrick on wool and knitting [50], and Robles \& Wiberg on building with ice [61]. Relatedly, studies in HCI of Do it Yourself (DIY) practices and paper crafting such as scrapbooking indicates that people are drawn to experiences involving making by the hand in tandem with the digital [13]. Crafters adopt an explorative attitude, allowing for new material opportunities and as such develop through trial and error. Moreover, online forums have turned out to play an important source for inspiration, providing opportunities for sharing ideas and tricks of the trade, and to meet and discuss with likeminded, see e.g. [13, $61,67]$. In practices of crafting with physical materials, things often happen by chance or serendipitously [44] providing opportunities and new paths of design [61]. In line with this, work around ideas of broken artefacts [34] and the Japanese design philosophy of wabi-sabi $[68,55]$, have explored principles of impermanence, incompletion, and imperfection. Importantly, Tsaknaki and Fernaeus [68] show how these principles bring new values to the processes of designing interactive artefacts that go beyond the rationalistic and instrumental goal of much mainstream technology.

\section{STUDY}

As stated above, the aim of this study was to understand the creation and maintenance of handmade bullet journals and the role they play in the practitioners' lives. To gather portrayals of their experiences and to analyze the broader range of practices involved, we conducted a qualitative interview study combined with social media observations. Based on Holz, Kronberger and Wagner [31] we treat social media as empirical sites similar to other social settings. We therefore consider the study of social media as a complementary way to understand the broader concerns of the bullet journal community, and various aspects of this specific form of personal data practice.

As a starting point for this work we followed five bullet journal communities from April 2017 to August 2018 using a qualitative approach of documentation and reflection. These communities were selected due to their size and that they had sustained for several years. They also represented a variety of motivations for maintaining a bullet journal such as improving productivity, health and overall wellbeing. The largest Facebook group that we followed was Bullet Journal Junkies, having roughly 145000 members. We also followed Bullet Journaling Mental Health and Mindfulness, Bullet Journal Tips and Tricks, Bullet Journal for Productivity as well as Bullet Journal Sverige (in Swedish). Further, we followed a number of youtubers oriented towards bullet journals at that time.

Our initial understanding of bullet journaling was developed based on observational data of these online communities. The purpose of this was to gain a broad understanding of bullet journaling practices, the appeal of paper-based journaling, and the role played by social media in this process. These communities differ in focus but as identified also in [1], they are about sharing best practices, show'n tell of useful tricks, and ways of integrating the journals in daily life. We followed these communities on a weekly basis, and gathered data through written observations and screen dumps, laying the foundation for our interview study. The data was analysed through reflective notes and thematic coding which provided insights to the practice of bullet journaling and the central concerns of the participants.

Based on our understanding of these communities we conducted seven in-depth interviews. Five were made faceto and two over Skype. The participants in our interview study were recruited from the Bullet Journal Sverige Facebook group. They volunteered to participate without compensation. The informants were all women. This reflects the vast majority of the participants in the bullet journal Facebook groups studied. All of them had part time or full employment, or owned their own businesses, three of them had families with children and they varied in age from early 20 's to mid 50's. One lived in the countryside, the others in cities. The interviews lasted between 50-75 minutes, five were made in person at the university premises and were audio recorded. Two interviews were made via Skype. These were recorded using Call Recorder for Skype. We also took pictures of pages in their journals when allowed. The interviews were transcribed by the two authors. 
The interviews were analyzed using open coding and thematic analysis [12]. Through iterative comparisons and juxtaposition of data from interviews with data from social media, we developed a number of broader themes based on the concerns and practices that recurred in our data. These themes were iterated and refined in order to identify how various pieces of data supported and contradicted each other.

In the following section, we present the results from our studies. All nick names and real names of informants and participants in various online groups have been anonymized, except for larger social media accounts with commercial intentions as these accounts are intended as public information for a large audience.

\section{FINDINGS}

We will begin by describing the general practices of bullet journaling as it is described both in [15] and numerous online forums. Then we move into the core themes that emerged in our study as central concerns for bullet journaling. More specifically, these address processes of handling of personal information, the role of crafting and creativity for expressing information, and finally the reflective work involved in the journaling processes.

The basic strategies of bullet journaling involve writing lists of plans, things to do, or to focus on (Figure 1) in chronological order (monthly, weekly and daily) as well as keeping track of achievements (e.g. tasks, exercising, hours of sleep, etc) and lists (collections) of activities to complete (e.g. personal project, career goals, etc.). Projects are defined as a set of activities with a clear goal that do not take more than a month to accomplish [15]. If a project is estimated to take longer time, it should be divided into smaller projects [15]. The main form of documentation is the bullet list that is simplified into 'rapid logging' through various types of bullets indicating the kind of items. Some of the more commonly used bullets are a square for task, a bullet for event and triangle for appointment (see also Figure 2).

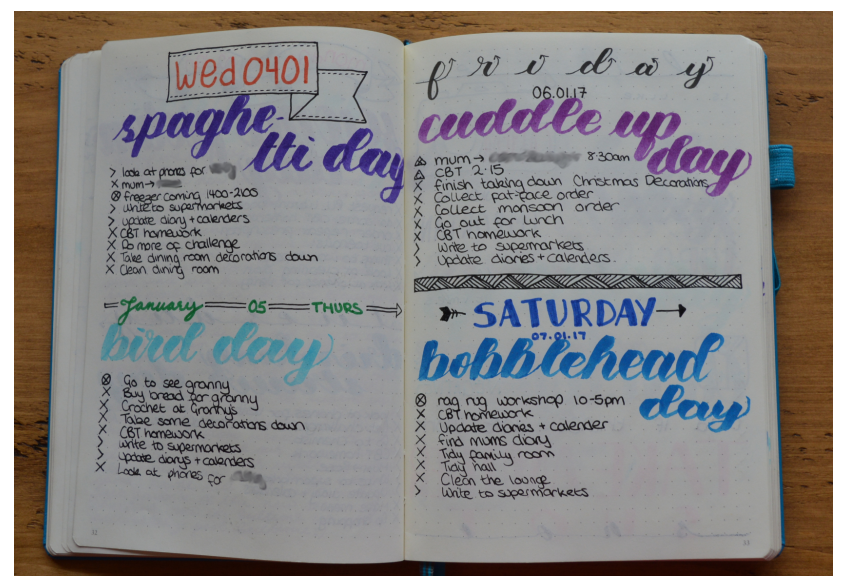

Figure 2 rapid logging @kayleighbulletjournals

One important technique is the migration of information between pages, i.e. moving items on the list that was not done to the next day, week or month. This provides opportunities to reflect on what items that have been achieved and what remains on the list, with the purpose of making clear what one puts time and energy into.

Craft and creativity are central to bullet journaling practice. People commonly adapt information structures to their needs as well as making their own personal designs and decorations. As described above, several social media communities are dedicated at sharing and discussing examples of how to visualize information, as well as sharing tips and tricks, see also [1].

\section{Information work}

Handling and maintaining a bullet journal involve many ways of curating information, in ways similar to other information management practices. However, bullet journaling is not only a way of saving and accessing information about daily tasks and activities. It also involves a continuous process of reconsideration, testing and tweaking the ways in which information is structured, represented, expressed and decorated. This is conducted in a dialectic process of considerations of personal and social circumstances, including planning and reflection about activities and achievements that comes with it. Especially, deliberations of what information to include and what to exclude in the journal play a central role in this process. We have labelled such information-oriented processes informational boundary work.

As described above, the blank pages allow an open-ended variety of informational content to be included, ranging from information about work, hobbies, religious practices as well as family and personal well-being. As such, the decision on what to include is highly personal, mirroring both current concerns and upcoming events in life. What to include is just as important as what to keep out. P1, for instance had a wellarticulated principle that she tries to follow:

“I want it [the journal] to be personal, don't want a lot of routines about cleaning, I think that stuff belongs to the whole family, it's my own stuff that interests me." (P1)

For P1, this principle work as a way of defining personal boundaries around the journal, with a deliberate idea for what information to include and not. The journal should be about her personal matters and not get "invaded" by family logistics, work and other mandatory things. This form of intentional and deliberate work with what to include and exclude in the journal is what we define as informational boundary work. In such work, the journal becomes a tool for clarifying the boundaries between social setting and work life, thereby, becoming a way to make room for things one finds important in life. As such, the information included provides an opportunity to purposefully manage one's attention in directions one finds meaningful, see also [37].

This form of informational boundary work help outline a focus in life, as well as remembering things of personal importance. This particular orientation to information can be 
recognized as a way of navigating between external demands and personal concerns, in order to stake out a personal trajectory.

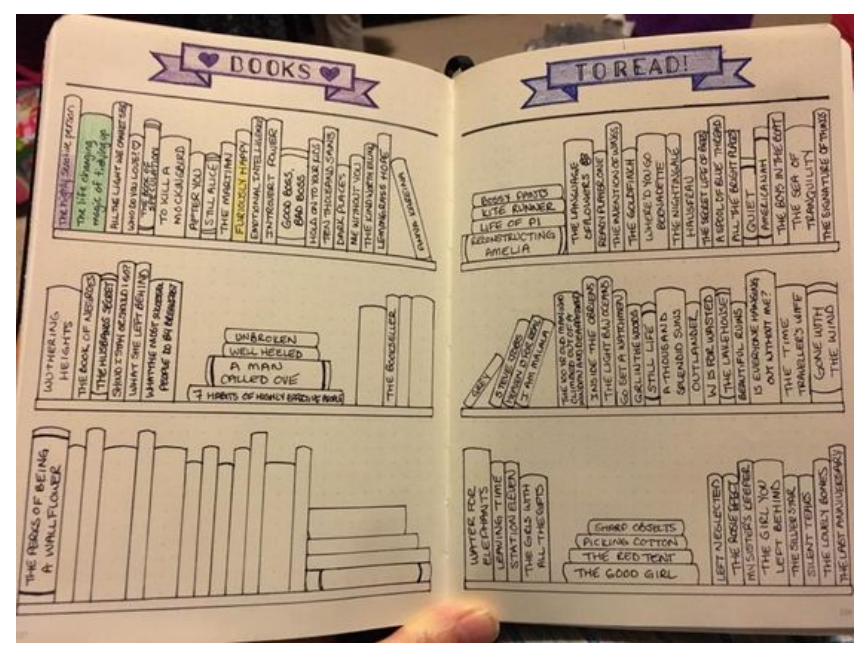

Figure 3: a list of books to read @productiveandpretty

The practice of informational boundary work often involves consideration of the things the bullet journalist finds good in life and the things that easily get lost in everyday chores and demands, including simple things such remembering certain books or movies (see Figure 3).

"It should be pleasurable, like books I want to read, films or series on Netflix, this gives me lists I can go back to and check out." (P1)

However, this looked different for different people. Some of the participants used their bullet journal as a tool to structure work activities and to strike a balance between work, school, and social life. It also involves ways of managing how information influences activities that they are engaged in. In that sense, controlling the information in the journals becomes a process of defining and creating the trajectories for the life one wants to lead.

The second information-oriented theme we call information selection work which expands on information boundary work, by further elaborating the strategies used in considering what to include in the journals. This process is dependent on a range of aspects such as the current life situation, spurs-of-the-moment, interaction with others, and things such as managing health and maintaining personal goals. In online forums and Facebook groups, selection and management of information about personal health and wellbeing are common topics. Logging and tracking such aspects are conducted through so-called habit trackers (see Figure 4). For several of our informants, these contributed to developing practical strategies for keeping focus on various aims and to remember what to prioritize in life when it comes to aspects such as food, sleep, exercise and personal wellbeing.

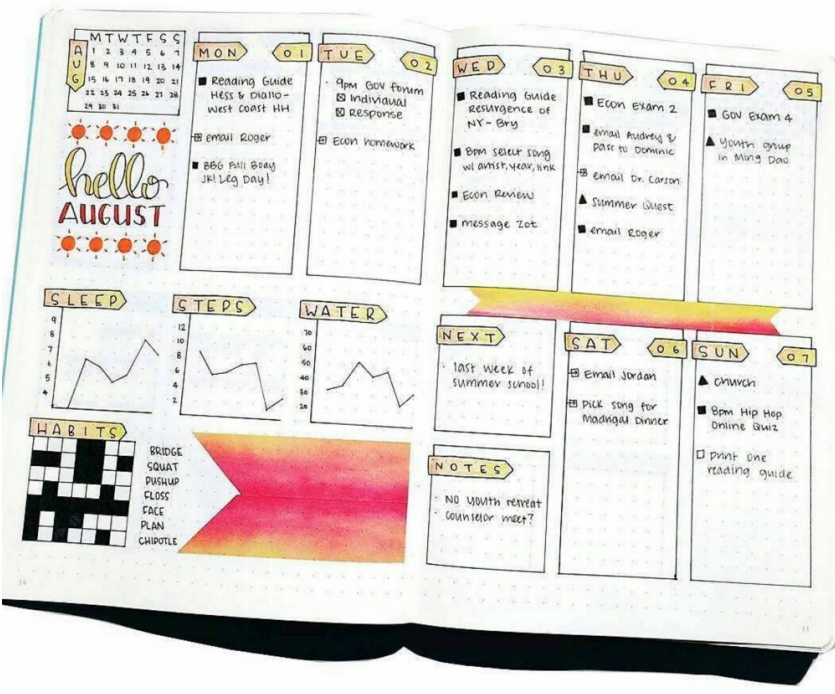

Figure 4 Weekly spread with habit trackers below left. From @bulletjournal.com

P2, for instance, described how she experienced that digital tools triggered stress. She found that bullet journaling supported her in organising the practical circumstances in order to stay away from things she found stressful. This included not stacking her days full of family chores, "mustdos" and work demands, and instead deliberately select things that save energy for other things in life.

"Thoughts about my health, my personal well-being and my energy in life. To me it is self-evident that I feel better and handle stress for instance if I exercise more and have routines for that, I also make room for that in my plans, since it takes time to walk those ten thousand steps so that I do not pack the calendar full of meetings and other stuff." (P2)

She expressed that bullet journaling engaged her in explicitly selecting information that supported activities of her own choice. Selection work could then be seen as way of taking control over their own personal life trajectories. Similarly, other informants came back to how they saw their journals as on-going reflections of the broader circumstances in their lives.

Furthermore, the attention to processes of information selection do not only concern what information to select, but also provided opportunities to engage with how things in life are related. Placing the sleep logs next to the daily plan in the journal creates a form of juxtaposition that makes it possible to see connections and make interpretation about how the information could be understood [66]. In line with life logging practices [46, 47], this active consideration of selecting and organising personal data helped our informants to direct their gaze towards things they find important and wanted to focus on. For instance, one informant used a mobile phone as a step counter. But rather than using the application in her phone for logging and analysing the 
number of steps she took, she manually transferred the information to a habit tracking table in her bullet journal.

"I write down number of steps per day, I use a step counter in my mobile phone, but I transfer it and I have as a goal that I set for myself... I also write down general stuff about health for both me and my daughter, such as information from doctors' appointments." (P2)

This way of reviewing and integrating various digital and non-digital sources of data is common among bullet journalists. P6 for instance, described her process of integrating data from google calendar like this:

"Definitely, I use Google calendar and in it I have all the bookings. / ... / On Sundays I always sit and plan my week and review the planning. And then I make my to-do list that is valid for the week as far as I can think of right then and there, /.../And then I also write that I have a dentist time, that coaching call, I'll meet this and that person and I will go and meet someone at the pub. And then when I do my daily [spread in the bullet journal], I write it down and that way it gets included." (P6)

While this process is time consuming, the informants' express that they experienced that they benefit from selecting specifically the information about themselves that they chose to and to keep it in a place where they have full control.

\section{Crafting and valuing the imperfect}

Let us move to the role of crafting in managing, relating to and interpreting information in bullet journaling. Physical interaction with information through crafting, drawing and writing by hand is essential to much of the experiences that emerges through bullet journaling. As described in the sections above, bullet journaling is largely about a detailed engagement of iteratively and creatively crafting information structures, as well as adding and editing informational content. Our informants brought up various reasons for what this ongoing process of crafting meant and how it was important to them. This ranged from the joy of variation, to improving representations on a particular page, to the fun playing with different aesthetics and expressions, or to adjust information to varying circumstances in life. Perhaps most importantly, they highlighted how the process of crafting gave meaning to their journals in fundamental ways.

Our observations from online social media show how strategies and techniques for handling errors and mistakes are widely discussed topics. There are numerous online videos for how error could be dealt with. Typical techniques include gluing pages together to extend available space, using razorblades to cut out faulty pages, covering mistakes with washi tapes or stickers, and drawing decorative figures to cover something up. This kind of refinement and repair is fundamental to the crafting of bullet journals and in engaging with what information to include. However, what is considered an error and when an error needs fixing is an individual matter. For instance, P3 had an elaborated idea around when something was creatively satisfying and not. She framed this through a notion she called the "drawing effect".

"Now, I still have to do this time planning. To me it becomes a shortcut for those of us who are not as crafty: "The drawing effect". A fight against perfectionism. You let it be ugly, skewed. There are faults and you have to live with them." (P3)

Similarly, P1 framed crafting and writing by hand as essential to the experiences created around bullet journaling. As a news journalist by profession, she emphasised how all forms of writing were essential to her and she was aware of how various practices and tools for writing served different purposes in her everyday text production. Writing by hand was not only a way of putting a personal touch to her journal, but indispensable to the whole process of creating and maintaining it:

"[For me] writing by hand is a part of a learning a process, the very technique is part of the process, something different than writing digitally, if I think about, this thing about setting goals for myself, goal achievement, analogue writing is part of this process" ( $\mathrm{P} 1)$

Crafting information in this way involves a simultaneous process of reflection and learning, and to ascribe meaning to the information in order to get a sense that it is uniquely about herself. Further, she discussed how elements or words on a page may be crooked, non-perfected, ugly and sometimes even difficult to read, and how these were important aspects of what these elements came to mean to her. She explained that the way something turns out on paper, such as if a to-do list becomes skewed, told her something about the situation when it was produced, about the state of mind at that point in time, and thereby, it carried meaning for its interpretation later in time. The characteristics that made the journal unique and personal at the same time helped her to remember and value its various items and entries. In this way, emotions and experiences of the creator of the journal become intimately tied to the journal itself and the specific ways its content is created, expressed and maintained.

Like in all kinds of crafting, iterative redesign, improvements and corrections are integral to the process. In an analogue practice such as bullet journaling - in which pens, paper, glue, tape, rulers, etc., are used to write, draw, and decorate - things do not always turn out as intended. Each action is produced somewhat differently, sometimes due to mistakes and errors, but most often due to small and un-intended variations in how a line was drawn, a letter written, or some decorative tape or sticker was place, (see Figure 5). Some informants described how they left flaws and glitches as they were. If the layout of a daily plan, a table or log did not turn out as they wanted or were not "creatively satisfying", they still chose to leave it as it were. All in all, they found these instances of imperfection to be crucial to their overall engagement with the information and what it came to mean to them.

\section{Personal aesthetics}

In our interview data as well as from notes from online forums, the experiences of beauty and joy in creating and using their journals were highlighted. Portraying personal information in a personally aesthetic fashion impacted bullet journalists' feelings towards certain tasks, and to the actual experience of carrying them out. For instance: 
"I feel that it [bullet journaling] is fun, and then when I look at my to-do list and it is really pretty, then I think that maybe it is not as difficult to get those things done ... it becomes fun to check off something and to do it... "(P4)

P4 pointed to a particular to-do list that she had crafted, and how the aesthetics influenced her feelings towards the different items. The list even made it less burdensome to get certain things done.

Furthermore, crafting of the journals was not only about adding aesthetics to personal information, but more importantly about crafting the specific details of how the information they decided to include should be represented and structured. Typical examples of this were the habit trackers designed by $\mathrm{P} 4$ to track sleep, mood, exercise, and other things that she wanted to attend to. Like most pages in her journal, these trackers included combinations of various creative expressions such as artistic lettering, doodling, use of decorative stickers, post-its and washi tape. The particular sleep $\log$ in Figure 5 consisted of a table with each line representing a day and each column the hour of day. The particular form of representation allowed her to use a coloured marker pen to indicate what hours during a day she had slept. It also gave her an overview of her sleep patterns over time. Since a daily sleep tracker is something to often return to, she had put a strip of tape at the right edge to easily find it. The practice surrounding her use of trackers suggest that the relation to information is characterized by feelings of attachment and ownership in the careful selection and crafting of informational content.

The engagement in crafting and tweaking often created motivation and joy. However, sometimes perfectionism concerning the journal became an obstacle to getting things done in life. In online forums, people sometimes expressed that they wanted to quit bullet journaling since they could not maintain the creative level they wanted to. An example of how crafting shaped the experience of information was P3's colour-coding of her weekly spreads. The purpose of this was to get a quick overview of the composition of tasks and activities of the week she had in front of her.

"Red means super-important. Brown, or poop colour, is for really hard things. Pink is fun. Then I can see if there is not enough fun over a week" (P3)

P3 related the choice of specific colours to the larger timeframe of her weekly spreads and how different colours meant different things with respect to the upcoming week. As such, colouring is a simple informational practice, but it served P3 both visually and structurally including ways of ascribing certain feelings towards various tasks and appointments and getting an overview of the balance between fun and work.

\section{Reflections and motivations through bullet journaling}

What emerges in our findings is the fact that the processes of crafting are often preliminary and imperfect. The combination of crafting and working with strategically selected personal information spurred insights about day-today activities. In what follows, we would like to bring further attention these aspects in relation to what it means to be productive.

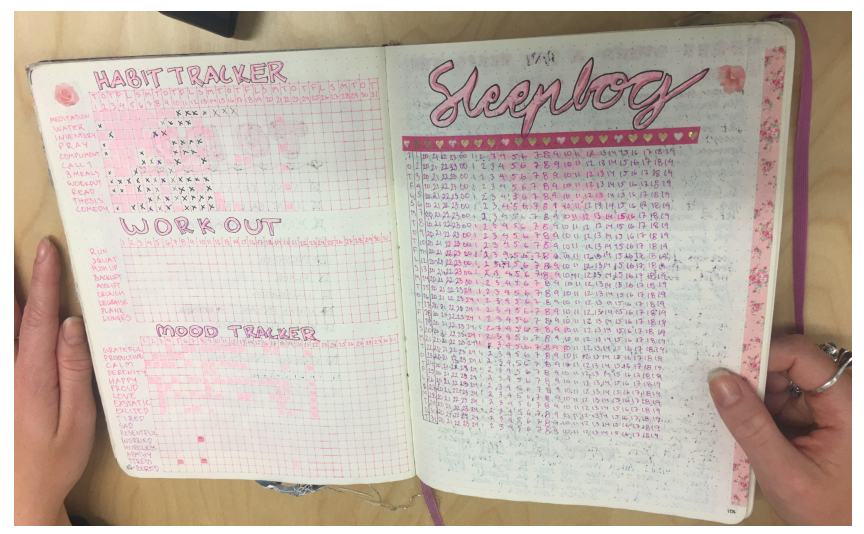

Figure 5: Habit trackers for sleep, mood, workout.

Gregg discusses "learning the art of productivity" and being on a constant "quest for organization" as two contemporary trends [28]. While one may want to resist the stress generated by increasing demands on personal productivity, it is difficult to completely resist to adhere to such norms.

One informant brought up how bullet journaling is presented by the inventor as a "mindfulness tool disguised as a planning tool", and that this was one of the things that she found so attractive about it. She found that bullet journaling offered possibilities of crafting, creativity and reflection things which she previously had a hard time to make room for in life:

"It gives you a break, a moment to yourself when you enter questions of how you want things, do I want this colour and that font. That gives me associations and a chance to reflect, the pure thing of doing things by hand." (P3)

Like the other informants, bullet journaling played multiple purposes to her. Besides being a tool to manage information for planning and organizing her life, it gave her opportunities to creatively engage with her own ideas and wishes in life. She talked about the openness of system as a key source to the multitude of purposes she found valuable, ranging from therapeutic aspects, to outlets for personal creativity, to being a tool for handling family logistics. Thereby, open-ended engagement with personal information provides ground for performing a form of identity work [33] and to create a personally meaningful narrative about oneself.

Let us now continue this topic in relation to how a bullet journal may work as a resource to resist getting overwhelmed with information.

"I try to consider how much time things take and what is realistic Previously, I have had serious problems with stress. I try to think about how much time things take. There is something about the digital [world] that triggers stress more, this is more relaxing. Possibly it has to do with the "neighbours" that calls for attention, like social media, time thieves." (P3)

To $\mathrm{P} 3$, the practice of keeping the information in analogue form avoids getting it tangled up with other digital sources of information in undesired ways - staying away from any 
"attention-seeking social media neighbours", as one of our informants framed it. The strategy of intentionally avoiding the abundance of information and the constant 'calls' from social media helped prioritize, remove, highlight, and save information without being limited to predefined information structures or processes of sharing or aggregation. Intentionally avoiding digital tools can thus work as a strategy to keep control over personal information and services one has not actively chosen to use.

The underlying motives for using bullet journaling as a strategy for managing personal information varied among our informants. Stress and well-being were common, while $\mathrm{P} 2$, emphasised what she called the "crafty" dimensions.

"And then I have always liked crafting, making paper and photo collages. In a way it gave me an excuse to be "handy" and "being capable" at the same time. Somehow it is the combination of these ... I think that it has something to do with making and creating with your hands." (P2)

She was drawn to bullet journaling by its character of crafting and the creative use of pen and paper. Combining such aspects with what she expressed as "being capable". This became a way for her to reflect on the expectations and challenges of her studies and work, while at the same time, placing it in the context of her personal interest. Drawing, writing and decorating her journal thereby became a way of reflecting on demands and expectations that she found burdensome sometimes even overwhelming. Bullet journaling thus become a way of responding to productivity demands in work, social and personal life.

\section{DISCUSSION}

As we have seen, the creative work of bullet journaling balances the lines between doodling and decoration, and curation of personal data in the creation of various individually designed information structures. In the following discussion, we elaborate on our findings, their consequences and how they expand on the research on personal informatics, in particular, in relation to design and research on lived informatics and novel data practices. By studying the experiences and motivations behind this practice, we have developed an empirical understanding of the opportunities for interaction design that emerge from a practice in which crafting and personal information meet. The variety of tools and materials used in paper-based crafting makes it possible for bullet journalists to take command over their information, and to structure, save, access and edit it in ways that are unique to each one of them.

The themes and personal narratives that surface in our study all represent less explored ways of curating and maintaining personal information. A craft-oriented aesthetics together with the personally constructed ways of engaging with data, stands in contrast to how most contemporary personal information management tools are designed with their focus on functional and instrumental dimensions [58]. By analyzing the application of bullet journals in everyday life and in particular the consequences of craft-based ways of engaging with data, we argue that this way of interacting with personal information provides a novel design potential for interaction design research. Thereby, this expands on Ayobi et al's [1] previous work on bullet journaling in HCI, which focused on users' emotional engagement and the potentials of such a practice to bridge the digital and analogue realms.

Let us now move on the three central themes of our discussion. Firstly, we discuss how bullet journaling resonates with, as well as resists, contemporary trends of productivity and personal development. Secondly, we discuss the consequences of this kind of open-ended and craft-based ways of organizing, selecting and dealing with information, and thirdly, we discuss how craft-oriented creative processes for dealing with personal information brings values of imperfection and aesthetics to the experiences of personal information.

\section{Resisting productivity}

Devotion to document, plan and manage one's time and self can be regarded as part of the modern rational project, and in many ways bullet journaling resonates with contemporary trends concerning data practices that put productivity and self-improvement at the core [43, 46, 47]. As argued by Gregg, productivity has become a hegemonial discourse, a taken for a granted point of departure in every aspects of life [28], However, the open-endedness of bullet journaling allows for possibilities of exploring and expressing oneself in ways that could be argued as liberating, becoming a response to such societal demands. Our informants experienced how bullet journaling supported them in turning away from what one informant framed as "business-like efficiency", and instead engage with their personal information in a way that let them put personal and social values at the core. This form of engagement with information resonates with Williams' autoethnographic study of tracking tools and weight loss technologies, in which he experienced technology, data and person as an interwoven whole, rather than as separate entities [72]. While bullet journaling clearly aligns with productivity imperatives, it can also be understood as a practice of what Nafus and Sherman call "soft resistance" [51]. When people reclaim the design, form and function of information about their everyday lives, they also take charge over its meaning, only letting others see what they explicitly let them, when and how. In this sense, bullet journaling could be interpreted as a form of critique - an oppositional action - towards the dominant and unavoidable technologies and infrastructures of our lives, such as search engines, cloud technologies, and messaging systems. Information practices that rely on such forms of interaction may let people get a sense of a regained control over at least parts of their personal information and what it should come to mean to them.

\section{Information, reflection and self-creation}

Our study shows how careful consideration of what pieces of information to include and exclude in the journals play an important role in deciding what aspects of life to orient one's attention towards. Some informants expressed that this 
engaged them in a process of taking control over things of importance to them. A key driver in this process is the continuous work of selecting what should be in the journals and what should not. Articulation of deliberate strategies for the boundaries for inclusion and exclusion of information and in what form, thereby becomes a way of reflecting over where they draw the lines between themselves, their families, and other important relations. We frame these processes as informational boundary work between the individuals and the context around them.

Consequently, this focus on the lived and experiential dimensions suggest a move away from aspects of rationality, efficiency and optimization in interaction with personal information. In line with notions such as lived informatics [58] and studies of similar data practices, e.g. [46, 47], the point of departure in this practice relies extensively on the social and personal context where information is produced [20, 21]. Thereby, planning, organization and logging of personal information through a process that focus on craft, design, and aesthetics puts personal values at the core and engages in what has been framed as identity work [74]. Similarly, in Elsden et al's [23] work on documentary informatics suggests a step away from considering data practices as only concerned with precision and objectivity, towards what they call poetic dimensions, capturing the experiential and imaginary aspects of personal data. This aligns with our informants' way of aesthetically portraying and designing their own data. The craft-based approach of bullet journaling thereby contributes to how personal informatics may be developed to broaden the ways of designing for people to engage with personal information.

Practitioners' ongoing processes of designing and redesigning of information structures can be understood as a form of care-taking of the content of their journals and consequently of themselves as individuals. Bullet journaling then illustrates a form of deliberate self-creation, manifested in the careful design of the journals in an on-going form of informational boundary work related to individual circumstances, goals, needs and wishes in life. Thereby, the portrayal and crafting of information becomes intimately intertwined with the practitioners' experiences of themselves and the trajectories they want to pursue in life. Crucial to a practice such as this, is the reflective relation between bullet journalists and the information included in their journals, a relation under continuous reconsideration and revision. We argue that this form of data practice creates a subjective framing to the interpretation of information. Personal data thereby becomes interwoven with individual activities and experiences - and with the practitioners' individual needs and desires. Designing their journal and the personal information becomes a part in co-creating activities and actions, a place to turn to for memories and reminders, and to help shift one's gaze towards things appreciated in life.

\section{Crafting the imperfect}

Let us move to the role played by the skills of crafting and writing by hand to the overall experience of bullet journaling. An important value in this, is the possibility of merging skills of crafting with things one finds important in life. Essential to this process is the fact that the content and structure of the journal is continuously revised, improved and tweaked. Seemingly simple actions such as deliberating over the choice of pen of a certain colour in order to express something fun, or choosing another colour to express something boring, becomes part of constructing the personal trajectory one is pursuing. On a surface level, lists, tables and trackers used by bullet journalist are the same as those found in most digital systems. However, through the process of crafting and maintaining these by hand, intimate ties are created between the individuals, their journals and their information. Thereby, a bullet journal is constantly in the making, and as such incomplete, preliminary and imperfect. If someone's to-do list or item in a future log turns out nice or ugly is partly a matter of skill, but also a consequence of how craft materials bring unexpected instances of change, a form of design orientation into the process [e.g. 13, 18, 34, 61]. Mixing two felt pens on a particular kind of paper might give an unforeseen colour mix. Importantly, such variations in how things turn out on paper, influence how the information is interpreted and what it comes to mean at a later point in time. These kind of crafting processes reflect recent work in interaction design concerning the Japanese design philosophy wabi-sabi $[68,55,40]$, which is based on the three principles of impermanence, incompletion, and imperfection. Tsaknaki and Fernaeus [68] show how these principles may be used to bring new values to the processes of designing interactive artefacts, allowing users to experience interactions beyond rationalistic values dominating current technology design. Similarly, layouts and doodles in a bullet journal always vary through glitches and small mistakes. This promotes an inherent form of change to the practice of bullet journaling, and consequently, to the narratives people create about them. One of our informants talked about this as "the drawing effect". Relatedly, in Ikemiya and Rosner's [ 34] work on the notion of worn media and broken probes, they discuss how the open-ended narratives people create around imperfect and impermanent objects stands in contrast to more rationalistic conceptions around novel technology [58]. Thus, welcoming that the imperfect and unexpected carries meaning and value [55].

\section{FINAL REMARKS}

For the participants of our study, their bullet journals are packed with subjectivity and personal dimensions, creating intimate ties between themselves, their information, and its expression. This turns interaction with personal information into a continuous process of design and reflection, rather than mere interaction and manipulation of (pre-defined) information structures. We argue that engaging with personal information in interactive systems in this fashion would 
make the interaction valuable and personally engaging beyond the rationalistic and instrumental purposes that govern mainstream technology development. Rethinking technologies for generating, storing, and managing of personal information in this fashion may contribute to reshaping users' ways of negotiating its meaning and to make room for establishing alternative narratives about themselves and their lives. We see a powerful opportunity for interaction design research to learn from these ways of treating ourselves - as well as information about us - as imperfect, as constructions in the making. Ultimately, contributing to the design of technologies that allow people to further engage in creating and caring for who they want to be.

\section{REFERENCES}

[1] Amid Ayobi, Tobias Sonne, Paul Marshall, and Anna L. Cox. 2018. Flexible and Mindful Self-Tracking: Design Implications from Paper Bullet Journals. In Proceedings of the 2018 CHI Conference on Human Factors in Computing Systems (CHI '18). ACM, New York, NY, USA, Paper 28, 14 pages. https://doi.org/10.1145/3173574.3173602

[2] Anna L. Cox. 2018. Flexible and Mindful SelfTracking: Design Implications from Paper Bullet Journals. In Proceedings of the 2018 CHI Conference on Human Factors in Computing Systems (CHI '18). ACM, New York, NY, USA, Paper 28, 14 pages. https://doi.org/10.1145/3173574.3173602

[3] Jeffrey Bardzell., Shaowen Bardzell., Szu-Yu Liu. 2019. Beautifying IoT: The Internet of Things as a Cultural Agenda. In: Soro A., Brereton M., Roe P. (eds) Social Internet of Things. Internet of Things (Technology, Communications and Computing). Springer, Cham.

[4] Steve Benford, Boriana Koleva, Anthony Quinn, Emily-Clare Thorn, Kevin Glover, William Preston, Adrian Hazzard, Stefan Rennick-Egglestone, Chris Greenhalgh, and Richard Mortier. 2017. Crafting Interactive Decoration. ACM Trans. Comput.-Hum. Interact. 24, 4, Article 26 (August 2017). https://doiorg.till.biblextern.sh.se/10.1145/3058552

[5] Ofer Bergman and Steve Whittaker. 2016. The Science of Managing Our Digital Stuff(1st ed.). The MIT Press.

[6] Ofer Bergman, Ruth Beyth-Marom, and Rafi Nachmias. 2006. The project fragmentation problem in personal information management. In Proceedings of the SIGCHI Conference on Human Factors in Computing Systems (CHI '06), Rebecca Grinter, Thomas Rodden, Paul Aoki, Ed Cutrell, Robin Jeffries, and Gary Olson (Eds.). ACM, New York, NY, USA, 271-274. http://dx.doi.org/10.1145/1124772.1124813

[7] Michael Bernstein, Max Van Kleek, David Karger, and M. C. Schraefel. 2008. Information scraps: How and why information eludes our personal information management tools. ACM Trans. Inf. Syst. 26, 4, Article 24 (October 2008), 46 pages. https://doi.org/10.1145/1402256.1402263

[8] Olha Bondarenko and Ruud Janssen. 2005. Documents at Hand: Learning from Paper to Improve Digital Technologies. In Proceedings of the SIGCHI Conference on Human Factors in Computing Systems (CHI '05). ACM, New York, NY, USA, 121-130. https://doiorg.till.biblextern.sh.se/10.1145/1054972.1054990

[9] Kirsten Boehner, Rogério DePaula, Paul Dourish, and Phoebe Sengers. 2007. How emotion is made and measured. Int. J. Hum.-Comput. Stud. 65, 4 (April 2007), 275-291. http://dx.doi.org/10.1016/j.ijhcs.2006.11.016

[10] Horatiu Bota, Paul N. Bennett, Ahmed Hassan Awadallah, and Susan T. Dumais. 2017. Self-Es: The Role of Emails-to-Self in Personal Information Management. In Proceedings of the 2017 Conference on Conference Human Information Interaction and Retrieval (CHIIR '17). ACM, New York, NY, USA, 205-214.

[11] Maarten den Braber. 2016. The Emergence of Quantified Self as a Data-driven Movement to Promote Health and Wellness. In Proceedings of the first Workshop on Lifelogging Tools and Applications (LTA '16). ACM, New York, NY, USA, 1-1. https://doi.org/10.1145/2983576.2983584

[12] Virginia Braun and Victoria Clarke. 2006. Using thematic analysis in psychology. Qualitative Research in Psychology, 3 (2). pp. 77-101. Qualitative Research in Psychology. http://dx.doi.org/10.1191/1478088706qp063oa

[13] Leah Buechley, Daniela K. Rosner, Eric Paulos, and Amanda Williams. 2009. DIY for CHI: methods, communities, and values of reuse and customization. In CHI '09 Extended Abstracts on Human Factors in Computing Systems (CHI EA '09). ACM, New York, NY, USA, 4823-4826. https://doi.org/10.1145/1520340.1520750

[14] Ryder Carroll. 2019. Bullet journaling. https://bulletjournal.com/. Last vistited 2019-09-19

[15] Ryder Carroll. 2018. The Bullet Journal Method. Fourth Estate Limited. 304 p.

[16] Csikszentmihalyi, M. (1996). Creativity. Flow and the psychology of discovery and invention. New York: Harper Perennial.

[17] Sarah Clinch, Paul Metzger, and Nigel Davies. 2014. Lifelogging for 'observer' view memories: an infrastructure approach. In Proceedings of the 2014 ACM International Joint Conference on Pervasive and Ubiquitous Computing: Adjunct Publication (UbiComp 
'14 Adjunct). ACM, New York, NY, USA, 1397-1404. https://doi.org/10.1145/2638728.2641721

[18] Kristin N. Dew and Daniela K. Rosner. 2018. Lessons from the Woodshop: Cultivating Design with Living Materials. In Proceedings of the 2018 CHI Conference on Human Factors in Computing Systems (CHI '18). ACM, New York, NY, USA, Paper 585, 12 pages. https://doi.org/10.1145/3173574.3174159

[19] Graham Dove, Kim Halskov, Jodi Forlizzi, and John Zimmerman. 2017. UX Design Innovation: Challenges for Working with Machine Learning as a Design Material. In Proceedings of the 2017 CHI Conference on Human Factors in Computing Systems (CHI '17). ACM, New York, NY, USA, 278-288. https://doi.org/10.1145/3025453.3025739

[20] Chris Elsden, David S. Kirk, and Abigail C. Durrant. 2016. A Quantified Past: Toward Design for Remembering With Personal Informatics. Hum.Comput. Interact. 31, 6 (November 2016), 518-557. http://dx.doi.org/10.1080/07370024.2015.1093422

[21] Chris Elsden, Abigail C. Durrant, and David S. Kirk. 2016. It's Just My History Isn't It?: Understanding Smart Journaling Practices. In Proceedings of the 2016 CHI Conference on Human Factors in Computing Systems (CHI '16). ACM, New York, NY, USA, 28192831. https://doi.org/10.1145/2858036.2858103

[22] Chris Elsden, Bettina Nissen, Andrew Garbett, David Chatting, David Kirk, and John Vines. 2016. Metadating: Exploring the Romance and Future of Personal Data. In Proceedings of the 2016 CHI Conference on Human Factors in Computing Systems (CHI '16). ACM, New York, NY, USA, 685-698. https://doi.org/10.1145/2858036.2858173

[23] Chris Elsden, Mark Selby, Abigail Durrant, and David Kirk. 2016. Fitter, happier, more productive: what to ask of a data-driven life. Interactions 23, 5 (August 2016), 45-45. https://doi.org/10.1145/2975388

[24] Chris Elsden, Abigail C. Durrant, David Chatting, and David S. Kirk. 2017. Designing Documentary Informatics. In Proceedings of the 2017 Conference on Designing Interactive Systems (DIS '17). ACM, New York, NY, USA, 649-661. DOI: https://doi.org/10.1145/3064663.3064714

[25] Umer Farooq. 2005. Eureka! past, present, and future of creativity research in HCI. XRDS 12, 2 (December 2005), 6-6. https://doi.org/10.1145/1144375.1144381

[26] Jonas Frich, Michael Mose Biskjaer, and Peter Dalsgaard. 2018. Why HCI and Creativity Research Must Collaborate to Develop New Creativity Support Tools. In Proceedings of the Technology, Mind, and Society (TechMindSociety '18). ACM, New York, NY, USA, Article 10, 6 pages. https://doi.org/10.1145/3183654.3183678
[27] Anthony Giddens. 1991. Modernity and Self-Identity Self and Society in the Late Modern Age. Polity Press

[28] Melissa Gregg. 2018. Counterproductive: Time Management in the Knowledge Economy. Duke University Press. 212 p.

[29] Shad Gross, Jeffrey Bardzell, and Shaowen Bardzell. 2013. Touch style: creativity in tangible experience design. In Proceedings of the 9th ACM Conference on Creativity \& Cognition (C\&C '13), Ellen Yi-Luen Do, Steven Dow, Jack Ox, Steve Smith, Kazushi Nishimoto, and Chek Tien Tan (Eds.). ACM, New York, NY, USA, 281-290.

http://doi.acm.org.till.biblextern.sh.se/10.1145/246662 7.2466653

[30] Dize Hilviu and Amon Rapp. 2015. Narrating the quantified self. In Adjunct Proceedings of the 2015 ACM International Joint Conference on Pervasive and Ubiquitous Computing and Proceedings of the 2015 ACM International Symposium on Wearable Computers (UbiComp/ISWC'15 Adjunct). ACM, New York, NY, USA, 1051-1056. https://doi.org/10.1145/2800835.28009

[31] Peter Holtz, Nicole Kronberger and Nicole Wagner. 2012. Analyzing Internet Forums: A Practical Guide. Journal of Media Psychology: Theories, Methods, and Applications. 24. 55-66. 10.1027/1864-1105/a000062

[32] K. Shannon Howard. 2018. Unplugging Popular Culture: Reconsidering Analog Technology, Materiality, and the "Digital Native". Routledge. Research in Cultural and Media Studies. $172 \mathrm{p}$

[33] Noura Howell, Laura Devendorf, Tomás Alfonso Vega Gálvez, Rundong Tian, and Kimiko Ryokai. 2018. Tensions of Data-Driven Reflection: A Case Study of Real-Time Emotional Biosensing. In Proceedings of the 2018 CHI Conference on Human Factors in Computing Systems (CHI '18). ACM, New York, NY, USA, Paper 431, 13 pages. https://doi.org/10.1145/3173574.3174005

[34] Miwa Ikemiya and Daniela K. Rosner. 2014. Broken probes: toward the design of worn media. Personal Ubiquitous Comput. 18, 3 (March 2014), 671-683. http://dx.doi.org/10.1007/s00779-013-0690-y

[35] Tim Ingold. 2013. Making: Anthropology, Archaeology, Art and Architecture. Routledge. London. UK.

[36] William Jones. 2007. Personal Information Management. Annual Rev. Info. Sci \& Technol. 41, 1 (December 2007), 453-504. http://dx.doi.org/10.1002/aris.144.v41:1

[37] William Jones, Robert Capra, Anne Diekema, Jaime Teevan, Manuel Pérez-Quiñones, Jesse David Dinneen, and Bradley Hemminger. 2015. "For Telling" the Present: Using the Delphi Method to 
Understand Personal Information Management Practices. In Proceedings of the 33rd Annual ACM Conference on Human Factors in Computing Systems (CHI '15). ACM, New York, NY, USA, 35133522

[38] William Jones, Susan Dumais \& Harry Bruce. 2002. Once found, what then? A study of "keeping" behaviors in the personal use of Web information. Proc. Am. Soc. Info. Sci. Tech., 39: 391-402. https://doi.org/10.1002/meet.1450390143

[39] William Jones and Kenneth M. Anderson. 2011. Many views, many modes, many tools ... one structure: Towards a Non-disruptive Integration of Personal Information. In Proceedings of the 22nd ACM conference on Hypertext and hypermedia (HT '11). ACM, New York, NY, USA, 113-122. http://dx.doi.org/10.1145/1995966.1995984

[40] Vaiva Kalnikaite, Abigail Sellen, Steve Whittaker, and David Kirk. 2010. Now let me see where i was: understanding how lifelogs mediate memory. In Proceedings of the SIGCHI Conference on Human Factors in Computing Systems (CHI '10). ACM, New York, NY, USA, 2045-2054. https://doi.org/10.1145/1753326.1753638

[41] Young-Ho Kim, Eun Kyoung Choe, Bongshin Lee, and Jinwook Seo. 2019. Understanding Personal Productivity: How Knowledge Workers Define, Evaluate, and Reflect on Their Productivity. In Proceedings of the $2019 \mathrm{CHI}$ Conference on Human Factors in Computing Systems (CHI '19). ACM, New York, NY, USA, Paper 615, 12 pages. DOI: https://doi.org/10.1145/3290605.3300845

[42] Lansdale MW. The psychology of personal information management. Applied Ergonomics. 1988;19(1):55-66. http://simson.net/ref/1988/Lansdale88.pdf

[43] Gilly Leshed and Phoebe Sengers. 2011. "I lie to myself that $\mathrm{i}$ have freedom in my own schedule": productivity tools and experiences of busyness. In Proceedings of the SIGCHI Conference on Human Factors in Computing Systems (CHI '11). ACM, New York, NY, USA, 905-914. https://doi.org/10.1145/1978942.1979077

[44] Rung-Huei Liang. (2012). Designing for unexpected encounters with digital products: Case studies of serendipity as felt experience. International Journal of Design, 6(1), 41-58.

[45] Georgia Lupi \& Stefanie Posavec. The dear data project. Retrieved December 20, 2019 from http://www.dear-data.com/theproject

[46] Deborah Lupton. 2014. Self-tracking cultures: towards a sociology of personal informatics. In Proceedings of the 26th Australian Computer-Human Interaction Conference on Designing Futures: the Future of
Design (OzCHI '14). ACM, New York, NY, USA, 7786. http://dx.doi.org/10.1145/2686612.2686623

[47] Deborah Lupton. 2016. The Quantified Self . Polity Press.

[48] John McCarthy, Peter Wright. 2005. Putting 'felt-life' at the centre of human-computer interaction (HCI), Cognition, Technology and Work, v.7 n.4, p.262-271, doi=10.1007/s10111-005-0011-y

[49] Malcolm McCullough. 1996. Abstracting Craft: The Practiced Digital Hand. MIT Press, Cambridge, MA, USA.

[50] J. Meissner and G. Fitzpatrick. 2017. Urban Knitters on Interweaving Craft, Technologies and Urban Participation. In Proceedings of the 8th International Conference on Communities and Technologies (C\&T '17). ACM, New York, NY, USA, 12-21. https://doiorg.till.biblextern.sh.se/10.1145/3083671.3083674

[51] Dawn Nafus and Jamie Sherman .2014. This one does not go up to 11: The quantified self movement as an alternative big data practice. International Journal of Communication 8(2014): 1784-1794.

[52] David M. Nichols and Sally Jo Cunningham. 2009. The use of paper in everyday student life. In Proceedings of the 10th International Conference NZ Chapter of the ACM's Special Interest Group on Human-Computer Interaction (CHINZ '09). ACM, New York, NY, USA, 65-68. http://dx .doi.org/10.1145/1577782.1577794

[53] Bettina Nissen and John Bowers. 2015. Data-Things: Digital Fabrication Situated within Participatory Data Translation Activities. In Proceedings of the 33rd Annual ACM Conference on Human Factors in Computing Systems (CHI '15). ACM, New York, NY, USA, 2467-2476. https://doi.org/10.1145/2702123.2702245

[54] William Odom and Tijs Duel. 2018. On the Design of OLO Radio: Investigating Metadata as a Design Material. In Proceedings of the 2018 CHI Conference on Human Factors in Computing Systems (CHI '18). ACM, New York, NY, USA, Paper 104, 9 pages. DOI: https://doi.org/10.1145/3173574.3173678

[55] Francesca Ostuzzi, Giuseppe Salvia, and Valentina Rognoli. 2011. The value of imperfection in industrial product. In Proceedings of the 2011 Conference on Designing Pleasurable Products and Interfaces (DPPI '11). ACM, New York, NY, USA, Article 46, 8 pages. https://doi.org/10.1145/2347504.2347554

[56] Stephen Purpura, Victoria Schwanda, Kaiton Williams, William Stubler, and Phoebe Sengers. 2011. Fit4life: the design of a persuasive technology promoting healthy behavior and ideal weight. In Proceedings of the SIGCHI Conference on Human Factors in Computing Systems (CHI '11). ACM, New York, NY, USA, 423-432. https://doi.org/10.1145/1978942.1979003 
[57] Yann Riche, Nathalie Henry Riche, Ken Hinckley, Sheri Panabaker, Sarah Fuelling, and Sarah Williams. 2017. As We May Ink?: Learning from Everyday Analog Pen Use to Improve Digital Ink Experiences. In Proceedings of the 2017 CHI Conference on Human Factors in Computing Systems (CHI '17). ACM, New York, NY, USA, 3241-3253. https://doi.org/10.1145/3025453.3025716

[58] John Rooksby, Mattias Rost, Alistair Morrison, and Matthew Chalmers. 2014. Personal tracking as lived informatics. In Proceedings of the SIGCHI Conference on Human Factors in Computing Systems (CHI '14). ACM, New York, NY, USA, 1163-1172. https://doi.org/10.1145/2556288.2557039

[59] Erica Robles and Mikael Wiberg. 2010. Texturing the "material turn" in interaction design. In Proceedings of the fourth international conference on Tangible, embedded, and embodied interaction (TEI '10). ACM, New York, NY, USA, 137-144. https://doi.org/10.1145/1709886.1709911

[60] Erica Robles and Mikael Wiberg. 2011. From materials to materiality: thinking of computation from within an Icehotel. Interactions 18, 1 (January 2011), 32-37. https://doi.org/10.1145/1897239.1897248

[61] Daniela K. Rosner. 2010. Mediated crafts: digital practices around creative handwork. In $\mathrm{CHI}$ '10 Extended Abstracts on Human Factors in Computing Systems (CHI EA '10). ACM, New York, NY, USA, 2955-2958. https://doi.org/10.1145/1753846.17538

[62] Runco, M. A. (2014). Creativity: Theories and Themes: Research, Development, and Practice. USA: Elsevier Academic Press.

[63] Pedro Sanches, Kristina Höök, Elsa Vaara, Claus Weymann, Markus Bylund, Pedro Ferreira, Nathalie Peira, and Marie Sjölinder. 2010. Mind the body!: designing a mobile stress management application encouraging personal reflection. In Proceedings of the 8th ACM Conference on Designing Interactive Systems (DIS '10). ACM, New York, NY, USA, 47-56. 10.1145/1858171.1858182 http://doi.acm.org/10.1145/1858171.1858182

[64] Abigail J. Sellen, Andrew Fogg, Mike Aitken, Steve Hodges, Carsten Rother, and Ken Wood. 2007. Do lifelogging technologies support memory for the past?: an experimental study using sensecam. In Proceedings of the SIGCHI Conference on Human Factors in Computing Systems (CHI '07). ACM, New York, NY, USA, 81-90. https://doi.org/10.1145/1240624.1240636

[65] Sarah Schoemann and Michael Nitsche. 2017. Needle as Input: Exploring Practice and Materiality When Crafting Becomes Computing. In Proceedings of the Eleventh International Conference on Tangible, Embedded, and Embodied Interaction (TEI '17). ACM,
New York, NY, USA, 299-308. https://doiorg.till.biblextern.sh.se/10.1145/3024969.3024999

[66] Lucy Suchman. 1997. Centers of coordination : a case and some themes. Chapter in Discourse, Tools, and Reasoning: Essays on Situated Cognition. ed. / L. Resnick; R. Säljö; C. Pontecorvo; B. Burge. Berlin : Springer-Verlag, 1997. p. 41-62.

[67] Joshua G. Tanenbaum, Amanda M. Williams, Audrey Desjardins, and Karen Tanenbaum. 2013. Democratizing technology: pleasure, utility and expressiveness in DIY and maker practice. In Proceedings of the SIGCHI Conference on Human Factors in Computing Systems (CHI '13). ACM, New York, NY, USA, 2603-2612. https://doi.org/10.1145/2470654.2481360

[68] Vasiliki Tsaknaki and Ylva Fernaeus. 2016. Expanding on Wabi-Sabi as a Design Resource in HCI. In Proceedings of the 2016 CHI Conference on Human Factors in Computing Systems (CHI '16). ACM, New York, NY, USA, 5970-5983. https://doi.org/10.1145/2858036.2858459

[69] Steve Whittaker. 2011. Personal information management: From information consumption to curation. Annual Rev. Info. Sci \& Technol. 45, 1 (January 2011), 1-62. http://dx.doi.org/10.1002/aris.2011.1440450108

[70] Steve Whittaker and Candace Sidner. 1996. Email overload: exploring personal information management of email. In Proceedings of the SIGCHI Conference on Human Factors in Computing Systems (CHI '96), Michael J. Tauber (Ed.). ACM, New York, NY, USA, 276-283. https://doi.org/10.1145/238386.238530.

[71] Steve Whittaker and Julia Hirschberg. 2001. The character, value, and management of personal paper archives. ACM Trans. Comput.-Hum. Interact. 8, 2 (June 2001), 150-170. http://dx.doi.org/10.1145/376929.376932

[72] Kaiton Williams. 2015. An anxious alliance. In Proceedings of The Fifth Decennial Aarhus Conference on Critical Alternatives (CA '15). Aarhus University Press 121-131. https://doi.org/10.7146/aahcc.v1i1.21146

[73] Whittaker, Steve. (2011). Personal Information Management: From Information Consumption to Curation. Annual Review of Information Science and Technology. 45. https://doi.org/10.1002/aris.2011.1440450108.

[74] Lee Humphreys. 2018. The Qualified Self. Social Media and the Accounting of Everyday Life. MIT Press. Cambridge. MA. USA 